\title{
Thermodynamics of Oils of Nutritional/Cosmetic Use: Bertholletia excelsa, Cocos nucifera, and Pterodon emarginatus Vogel
}

\author{
Marta A. Pires ${ }^{1}$, Rebecca S. Andrade ${ }^{2 *}$, Miguel Iglesias ${ }^{3}$ \\ ${ }^{1}$ Mauricio de Nassau University; Salvador, Bahia; ${ }^{2}$ Federal University of Recôncavo da Bahia; Feira de Santana, Bahia; \\ ${ }^{3}$ Federal University of Bahia; Salvador, Bahia, Brazil
}

\begin{abstract}
This paper contains the results of a new experimental study about the temperature effect on density and ultrasonic velocity for Brazil nut (Bertholletia excelsa), coconut (Cocos nucifera), and sucupira (Pterodon emarginatus Vogel) oils. Isentropic compressibilities and isobaric expansibilities were computed from the experimental magnitudes as a function of temperature. Halvorsen's model (HM), and Collision Factor Theory (CFT) were selected for the prediction of these properties due to their wide range of application and easy computation. An accurate response was observed, despite the use of several simplifications as molecular group contribution procedures for estimation of theoretic criticals points of the fatty acids and the complex nature of the studied fluids.

Keywords: Thermodynamic Properties. Vegetable Oil. Theoretical Model. Estimation. Functional Group Contribution.
\end{abstract}

\section{Introduction}

Thermodynamic properties and phase equilibria data are the most critical parameters required in the design of equipment and processes, as well as predictions and simulations in food technology. Knowledge of these magnitudes as a function of operation magnitudes is of practical interest to the industrial manufacture of fats and oils. Thermal and mechanical procedures applied in the oil industry are closely related to their temperature and pressure dependence. Despite their economic importance, no systematic projects of consistent thermodynamic properties of fats and oils have been developed until now, and data for these kinds of compounds is relatively lacking. Different works published previously report data compilations of physical and thermal properties of fats and oils [1-5], but this information is not systematic, it is dispersed and many physicochemical properties have not been studied adequately. The fat and oils are biological, and they are not simple or

Received on 7 September 2020; revised 16 September 2020. Address for correspondence:Rebecca S. Andrade. Universidade Federal do Recôncavo da Bahia, Av. Centenário, 697, 44042280 Feira de Santana, Brazil.. Phone/Fax: (71) 3283-9805. E-mail rebecca.andrade@ufrb.edu.br.

J Bioeng. Tech. Appl. Health 2020;3(4):347-353.

C 2020 by SENAI CIMATEC. All rights reserved. one-molecular-structured. Their thermodynamic properties are strongly dependent on double-bound presence and position into the original molecular structure, chain length, nature of fatty acids, and molecular package of esters into solvents. Among the above indicated thermodynamic properties of solvents, volumetric and ultrasonic magnitudes have proved especially informative in elucidating the complex molecular interaction into the liquid phase. These values are of real core interest for direct industrial applications and theoretical predictive model development. The oils studied here have in common, in addition to growing economic importance, applications in food, medical or cosmetic uses, an enormous potential into emerging areas (nutraceuticals, phytotherapeutics, among others), and, at the same time, a severe gap in terms of thermodynamic data disposable into open literature. Fats and oils generate triglycerides, three molecules of fatty acids joined to a glycerol molecule. The chain length of the fatty acids and their organization on the glycerol backbone vary greatly, although in most of the edible oils it is with 16 and 18 carbons. The triacylglycerol is often considered the main chemical structure when developing estimative studies on the thermophysical properties of oils.

The Rackett equation, described from the Halvorsen method (HM) [6], was tested for density estimation. This method requires the critical 
properties of the fatty acids and considers their composition as input. The Collision Factor Theory (CFT) used the Wada method [7-9] for estimation of ultrasonic velocity of the enclosed fatty acids and the evaluation of their collision factors chosen for prediction of ultrasonic velocity. So, the tested models offer accurate results of the studied thermodynamic magnitudes, despite geometrical simplifications and the use of estimated critical dimensions by the Constantinou-Gani group contribution method [10].

\section{Materials and Methods}

The oils (cold-pressed quality), supplied by usual local providers, were stored in sunlight protected form and constant humidity and temperature in our laboratory. They were analyzed to determine their fatty acid compositions, the procedure being described earlier [11,12]. The average molar mass was computed as follows:

$$
M_{\text {oil }}=3 \cdot\left(\sum_{i=1}^{N} x_{i} \cdot M_{i}\right)+2 \cdot M_{\mathrm{CH}_{2}}+M_{C H}
$$

xi the molar fraction and Mi the molar mass of each fatty acid without a proton, $\mathrm{N}$ the number of fatty acids found by analysis, and $\mathrm{MCH}_{2}$ and $\mathrm{MCH}$ are the molar mass contributions of glyceride molecule residue. The variation in the composition between different samples affects mainly the mono and polyunsaturated fatty acids, the change in molar mass being lower than $\pm 1 \mathrm{~g}$ $\mathrm{mol}^{-1}$. The molar mass and fatty acids composition are gathered in Table 1. Densities and ultrasonic velocities were measured with an Anton Paar DSA$5000 \mathrm{M}$ vibrational tube densimeter and sound analyzer, with a resolution of $10^{-5} \mathrm{gcm}^{-3}$ and $1 \mathrm{~ms}^{-1}$. Apparatus calibration was performed periodically following vendor instructions using Millipore quality water and ambient air at each temperature. Accuracy in the measurement temperature was better than $\pm 10^{-2} \mathrm{~K}$ through a temperature control device that applies the Peltier principle to maintain isothermal conditions during the measurements. The experimental and disposable literature data of the oils at $298.15 \mathrm{~K}$ are gathered in Table 1.

\section{Results}

The measured physical properties were correlated as a function of temperature using Eq. 2:

$$
P=\sum_{i=0}^{N} A_{i} T^{i}
$$

where $\mathrm{P}$ is density $\left(\mathrm{gcm}^{-3}\right)$ or ultrasonic velocity $\left(\mathrm{ms}^{-1}\right), \mathrm{T}$ is the absolute temperature in Kelvin, and $\mathrm{Ai}$ is the fitting parameters. $\mathrm{N}$ stands for the extension of the mathematical series, optimized through the Bevington test. The fitting parameters were obtained by the unweighted least squared method applying a fitting Marquardt algorithm. The root means square deviations were computed using Eq. 3, where $\mathrm{z}$ is the value of the property, and $\mathrm{nDAT}$ is the number of experimental data.

$$
\sigma=\left(\frac{\sum_{i=1}^{n_{\mathrm{DAT}}}\left(z_{\text {exp }}-z_{\text {pred }}\right)^{2}}{n_{\mathrm{DAT}}}\right)^{1 / 2}
$$

Fitting parameters of Eq. 2 and the root mean square deviations (Eq. 3) are gathered in Table 2. In Figures $1 \mathrm{a}, 1 \mathrm{~b}$, and $2 \mathrm{a}$, the temperature trend of density, ultrasonic velocity, and isentropic compressibility (computed by the Newton-Laplace equation from density and ultrasonic velocity) are gathered. These figures show a decrease in density and ultrasonic speed when the temperature rises due to a sharp lowering of efficiency in terms of molecular structuration into the bulk phase of triacylglycerol. Progressively higher molecular kinetics by heightening temperatures and steric hindrance of heavy molecular structures produces a growing difficulty in packing molecules. As observed in Figure 1a, different collections of density data for Brazil nut and coconut oil are disposable in the open literature. As far as we 
Table 1. Molar mass, fatty acids compositions and experimental and literature data of density $\left(\mathrm{gcm}^{-3}\right)$ and ultrasonic velocity $\left(\mathrm{ms}^{-1}\right)$ for the studied vegetable oils at $298.15 \mathrm{~K}$

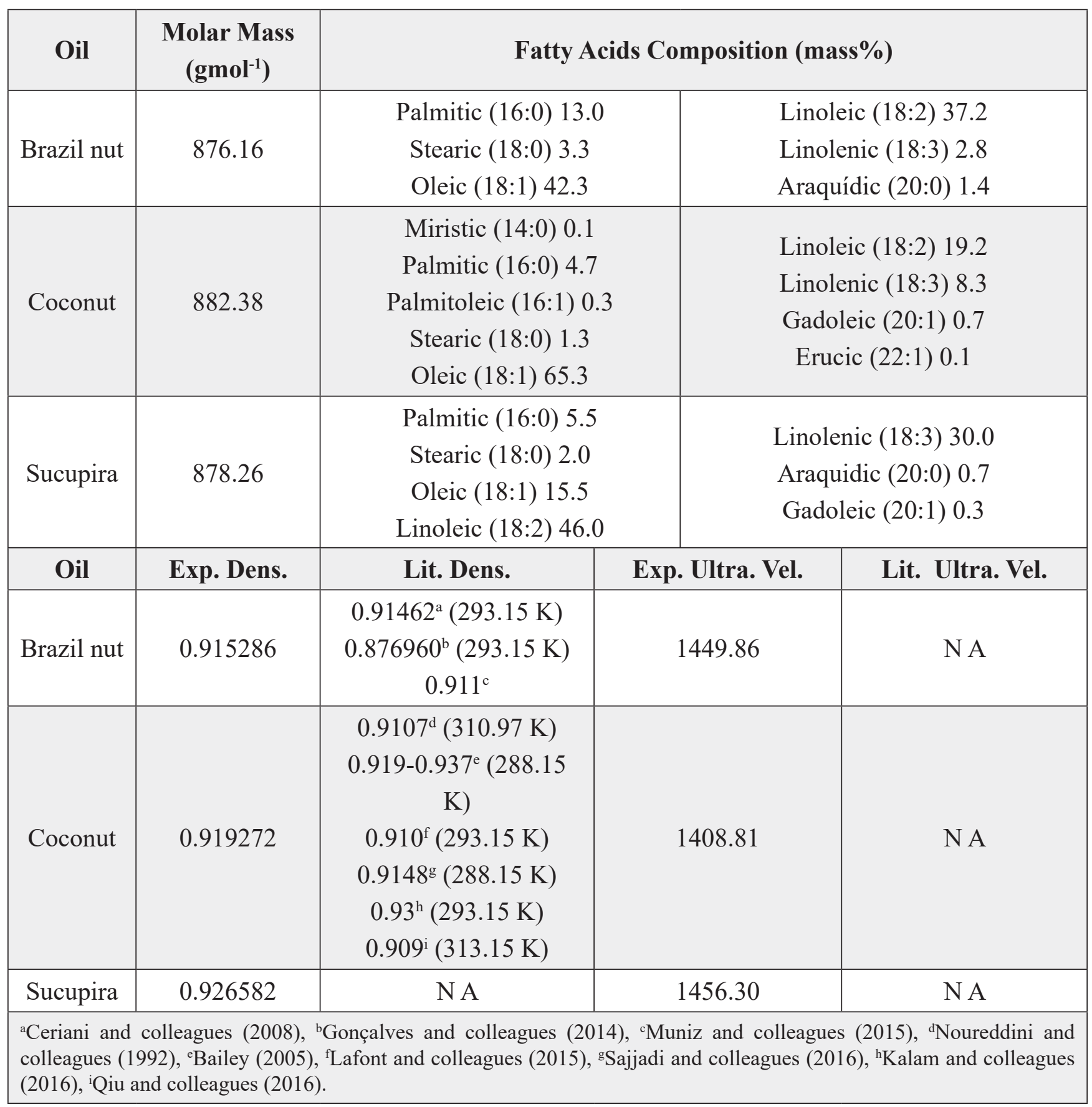

know, our new data on the density of sucupira oil are the first to be published. For Brazil nut oil, the three available collections are those of Ceriani and colleagues (2008), Gonçalves and colleagues (2014), and Muniz and colleagues (2015) [13-15].
Only the first author shows an analysis as a function of temperature (only six experimental points). All of them gather lower values than our experimental measurements, Gonçalves and colleagues (2014) show an unrealistic value $(4.5 \%$ of deviation 
Table 2. Parameters of Eq. 2 for 288.15-323.15 K and the corresponding root mean square deviations (Eq 3).

\begin{tabular}{|c|c|c|c|c|c|c|c|c|c|c|}
\hline \multicolumn{5}{|c|}{$\rho /\left(\mathrm{gcm}^{-3}\right)$} & \multicolumn{6}{|c|}{$\mathbf{u} /\left(\mathrm{ms}^{-1}\right)$} \\
\hline Oil & Ao & $\mathbf{A}_{1}$ & $\mathbf{A}_{2}$ & $\mathbf{A}_{3}$ & $\boldsymbol{\sigma}$ & Ao & $\mathbf{A}_{1}$ & $\mathbf{A}_{2}$ & $\mathbf{A}_{3}$ & $\boldsymbol{\sigma}$ \\
\hline Brazil nut & 1.283313 & $-2.279389 \mathrm{e}-3$ & $5.162837 \mathrm{e}-6$ & $-5.560350 \mathrm{e}-9$ & $1.540 \mathrm{e}-10$ & 3754.551308 & -15.344744 & 0.036297 & $-3.608038 \mathrm{e}-5$ & $9.231 \mathrm{e}-2$ \\
\hline Coconut & 1.225855 & $-1.533320 \mathrm{e}-3$ & $2.372553 \mathrm{e}-6$ & $-2.276184 \mathrm{e}-9$ & $0.574 \mathrm{e}-11$ & 5601.527929 & -33.106210 & 0.091952 & $-9.417774 \mathrm{e}-5$ & $0.306 \mathrm{e}-2$ \\
\hline Sucupira & 1.183274 & $-1.154745 \mathrm{e}-3$ & $1.382130 \mathrm{e}-6$ & $-1.330648 \mathrm{e}-9$ & $0.436 \mathrm{e}-11$ & 3105.584507 & -8.832402 & 0.014672 & $-1.207929 \mathrm{e}-5$ & $2.428 \mathrm{e}-2$ \\
\hline
\end{tabular}

from our data) far away from the other literature collections. The other references, Ceriani and colleagues (2008), and Muniz and colleagues (2015), are slightly lower than our collection $(0.5 \%$ of deviation), but with a similar trend in terms of evolution with temperature. For coconut oil, many references would be found, but only the first of them gathers values as a function of temperature. Noureddini and Qiu's works $[16,17]$ are coincident with our experimental data. The other collections show extreme deviations from our measurements [18-20]. Such differences are probably related to the difficulty in identifying the origin of raw material for oil production, the industrial process applied to obtain the oil, and the purity grade of the oil used in these earlier studies. There is no information in these works if the used oil is of refined or virgin nature, or about the conservation procedure or possible applied purification pre-treatments. No values were found in the open literature for the ultrasonic velocity of these oils. Our new collections of ultrasonic velocities will also be the first ones to be published. In Figure 1b, our experimental data of ultrasonic velocities are gathered. Analogously, the ultrasonic velocity shows a decreasing trend with rising temperatures, with a similar trend for Brazil nut and sucupira oil. The experimental measurements for coconut oil are presented only at the range $293.15-323.15 \mathrm{~K}$ due to the high gelling point of this oil. As expected, the isentropic compressibilities increase when the temperature rises for the three oils due to the inverse relation of this magnitude with density and ultrasonic velocity.

A frequently applied derived quantity is the temperature dependence of volumetric properties, which is expressed as isobaric expansibility or thermal expansion coefficient $(\alpha)$. The data reported in the literature currently shows only values of the thermal expansion coefficients both of pure compounds and its mixtures, showing the relative changes in density, calculated through $(-\Delta r / r)$ as a function of temperature, and assuming that a remains constant over the temperature range. As in the case of pure chemicals, these oils can be computed by the following expression:

$$
\alpha=-\left(\frac{\partial \ln \rho}{\partial \mathrm{T}}\right)_{\mathrm{P}, \mathrm{x}}
$$

Figure 1a presents the strong temperature dependence of density. An isobaric expansibility of the Brazil nut (Bertholletia excelsa), coconut (Cocos nucifera), and sucupira (Pterodon emarginatus Vogel) oils attend to this relation (Figure 2b). As observed, they all amount to negative values, but only with sucupira oil the isobaric expansibility diminish almost linearly. Both other oils show maxima at the studied temperature range (294.15 K for Brazil nut oil and $306.15 \mathrm{~K}$ for coconut oil).

Constantino and Gani [10] developed an advanced group contribution method for critical point estimation of covalent molecules based on the UNIFAC molecular groups. This procedure allows for a second-order level of contributions, overcoming the limitation of traditional group contribution models that cannot distinguish isomers or resonance structures. This method was applied to obtain the critical point of the fatty acids enclosed into the studied oils and then used in the prediction density method that was indicated above. The observed deviations, when 
compared with the database, are negligible. The physical property packages used in powerful chemical simulators typically rely on generalized equations for predicting properties as a function of temperature, pressure, among others. In the last few years, despite the success of developing several procedures of density estimation for pure compounds or mixtures, only a few of them may be of practical application and high accuracy for fats and oils. One proposed correlation that holds promise for application to oils is the Rackett equation of state, as well as the modification by Spencer and Danner. The procedure proposed by Halvorsen and colleagues using these equations has proven to be accurate, only requiring critical magnitudes for the enclosed fatty acids and their composition into the oil. If these magnitudes are not known, they must be estimated as indicated above. The procedure of Halvorsen is described as follows:

$$
\rho=\frac{\sum \mathrm{x}_{\mathrm{i}} \cdot \mathrm{M}_{\mathrm{i}}}{\mathrm{R} \cdot\left(\frac{\sum \mathrm{x}_{\mathrm{i}} \cdot \mathrm{T}_{\mathrm{ci}}}{\mathrm{P}_{\mathrm{ci}}}\right) \cdot\left(\sum \mathrm{x}_{\mathrm{i}} \cdot \beta_{\mathrm{i}}\right)^{\left[1+\left(1-\mathrm{T}_{\mathrm{r}}\right)^{2 / 7}\right]}}+\mathrm{F}_{\mathrm{C}}
$$

where $r$ is the oil density, $x i$ is the mole fraction of fatty acids into that oil, Mi is the molar mass of each fatty acid, $\mathrm{R}$ is the universal constant of gases, Pci is the critical pressure of each fatty acid, and $\operatorname{Tr}$ is the reduced temperature. The $\mathrm{b}$ parameter is the compressibility factor for the original equation of Rackett $(\mathrm{Zc})$ or an acentric factor-dependent parameter if we use the modified Rackett equation (ZRA). Kay's rule is used to compute the pseudocritical temperature, and FC is a correction factor proposed by Halvorsen that depends on the oil structure backbone. Table 3 shows the root square deviations for density values by Halvorsen's model (HM) versus experimental data at $298.15 \mathrm{~K}$.

Ultrasonic velocity has been systematically measured in recent years, but this kind of data is still extremely scarce for fats and oils. The experimental data were compared with the values obtained by the Collision Factor Theory (CFT) [7-9], which is dependent on the collision factors among molecules as a function of temperature:

$$
\mathrm{u}=\frac{\mathrm{u}_{\infty} \cdot\left(\sum_{\mathrm{i}=1}^{\mathrm{N}}\left(\mathrm{x}_{\mathrm{i}} \cdot \mathrm{S}_{\mathrm{i}}\right)\right) \cdot\left(\sum_{\mathrm{i}=1}^{\mathrm{N}}\left(\mathrm{x}_{\mathrm{i}} \cdot \mathrm{B}_{\mathrm{i}}\right)\right)}{\mathrm{V}}
$$

where $\mathrm{u} \infty$ is $1600 \mathrm{~m} / \mathrm{s}, \mathrm{Si}$ is the collision factor of each fatty acid, $\mathrm{Bi}$ is the molecular volume of each fatty acid, and $\mathrm{V}$ is the molar volume considering each oil a mixture of fatty acids attending to the composition (Table 1). The collision factors ( $\mathrm{Si}$ ) were estimated using the Wada method, and the molecular volume by Bondi contribution model for each fatty acid. The deviations for the CFT method are gathered in Table 3 .

Table 3. Root mean square deviations $\left(\mathrm{g} / \mathrm{cm}^{3}\right)$ for Halvorsen model (HM) density prediction and deviations $(\mathrm{m} / \mathrm{s})$ for the Collision Factor Theory (CFT) ultrasonic velocity prediction at $298.15 \mathrm{~K}$.

\section{Conclusion}

\begin{tabular}{lcc}
\hline Oil & $\begin{array}{c}\text { Halvorsen } \\
\text { Model }\end{array}$ & $\begin{array}{c}\text { Collision Factor } \\
\text { Theory }\end{array}$ \\
\hline Brazil nut & 0.015165 & 3.07 \\
Coconut & 0.053932 & 3.57 \\
Sucupira & 0.023490 & 5.07 \\
\hline
\end{tabular}

This paper contains the results of a new experimental study about the effect of temperature on density, and ultrasonic velocity for Brazil nut (Bertholletia excelsa), coconut (Cocos nucifera), and sucupira (Pterodon emarginatus Vogel) oils due to their rising economic value and potential in emerging areas as nutraceuticals and phytotherapy. We summarized our conclusions following the points: The tested methods Halvorsen's model (HM), and the Collision Factor Theory (CFT) showed the accurate capability of prediction of the measured magnitudes at the range of application, 
Figure 1. Dependence of temperature of experimental (a) density and (b) ultrasonic velocity of Brazil nut (Bertholletia excelsa), coconut (Cocos nucifera), and sucupira (Pterodon emarginatus Vogel) oils and available open literature data.
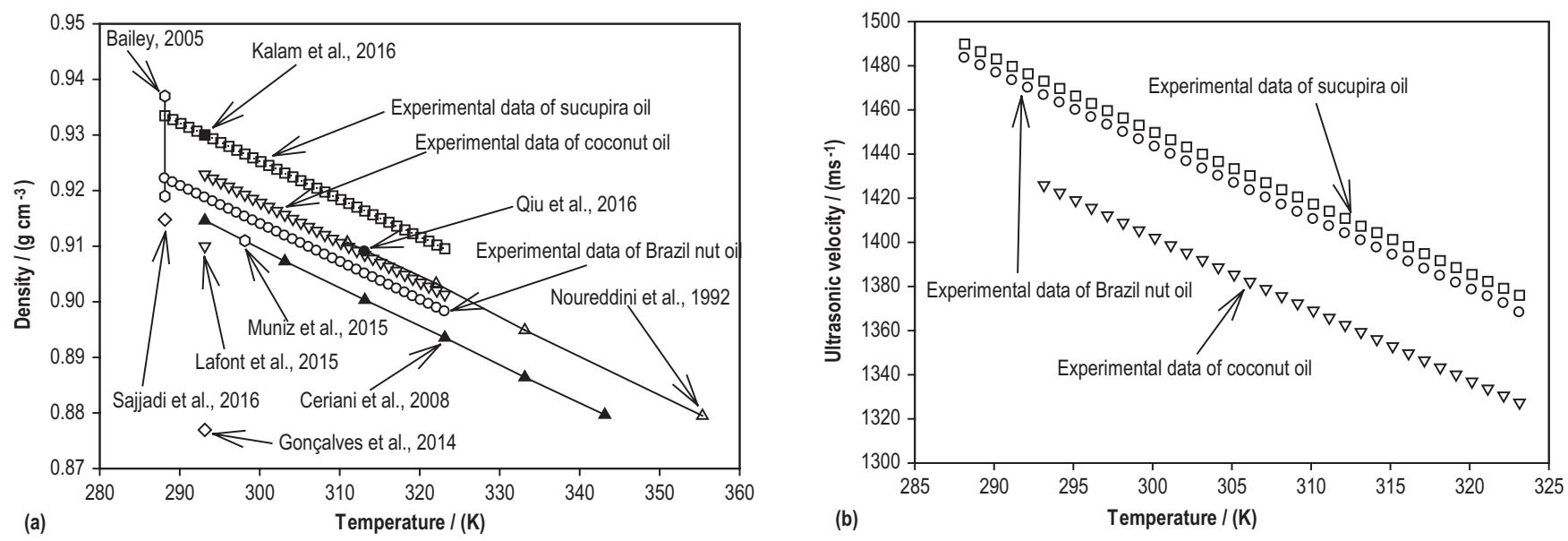

Source: By authors.

Figure 2. Dependence of temperature of experimental (a) isentropic compressibility and (b) isobaric expansibility of Brazil nut (Bertholletia excelsa), coconut (Cocos nucifera), and sucupira (Pterodon emarginatus Vogel) oils.
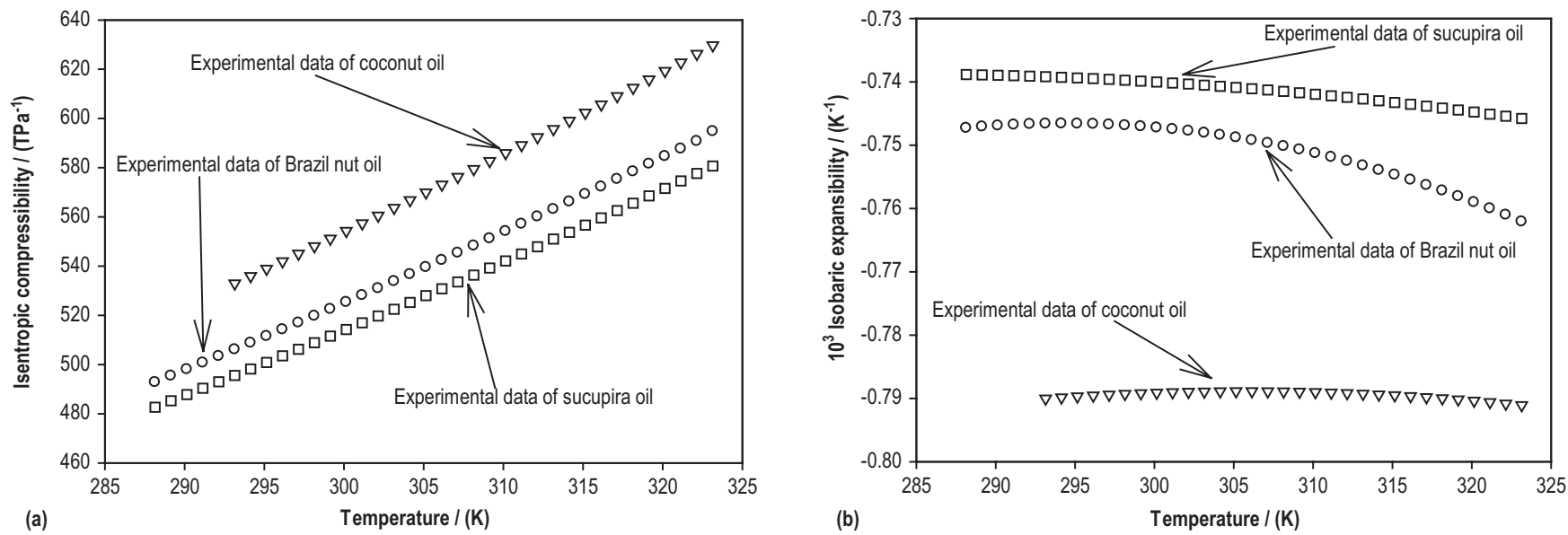

Source: By authors.

despite different simplifying assumptions, the use of estimated critical dimensions by molecular group contribution approach, and the complex nature of the studied fluids. A review of the physical properties of Brazil nut (Bertholletia excelsa), coconut (Cocos nucifera), and sucupira (Pterodon emarginatus Vogel) oil revealed a critical gap in terms of accurate and quality thermodynamic data. The measured experimental collections of density and ultrasonic velocity contribute to a better characterization of these vegetable 
oils and increase the disposable data for theoretical works and modeling/simulation of macromolecules.

\section{References}

1. Gunstone FD. Vegetable oils in food technology: composition, properties and uses. Blackwell Science Ltd., Oxford, 2002.

2. Heldman DR, Lund DB, Sabliov C. Handbook of food engineering. $2^{\text {nd }}$ ed., CRC Press, New York, 2006.

3. Shafiur-Rahman M. Food properties handbook. $2^{\text {nd }}$ ed., CRC Press, New York, 2009.

4. Murcott A, Belasco W, Jackson P. The handbook of food research. Bloomsbury Academic, New York, 2013.

5. Varzakas T, Tzia C. Food engineering handbook CRC Press, New York, 2014.

6. Halvorsen JD, Mammel WC, Clements LD. Density estimation for fatty acids and vegetable oils based on their fatty acid composition. JAOCS 1993;70:875880 .

7. Nutsch-kuhnkies R. Sound velocities of binary mixtures and solutions. Acustica 1965;15:383388.

8. Schaffs W. Problem of a theoretical calculation of velocity of sound for binary liquid mixtures. Acustica 1975;33:272-276.

9. Freitas SD, Cunha DL, Reis RA, Lima AS, Daridon JL, Coutinho JAP, Paredes MLL. Application of Wada's group contribution method to the prediction of the speed of sound of biodiesel. Energy \& Fuels 2013;27:1365-1370.

10. Constantinou L, Gani R. New group contribution method for estimating properties of pure compounds. AIChE J 1994;40:1697-1710.
11. Gonzalez C, Resa JM, Ruiz A, Gutierrez JI. Densities of mixtures containing n-alkanes with sunflower seed oil at different temperatures. J Chem Eng Data 1996;41:796-798.

12. Andrade RS, Matos M, Iglesias M, Gonzalez C. Temperature influence on thermodynamic properties of argan (Argania spinosa),neem (Azadirachta indica) and common walnut (Juglans regia L.) oils. Int J Eng Res Tecnol 2016;5(10):160-166.

13. Ceriani R, Paiva FR, Gonçalves CB, Batista EAC, Meirelles AJA. Densities and viscosities of vegetable oils of nutritional value. J Chem Eng Data 2008;53:1846-1853.

14. Gonçalves JD, Aznar M, Santos GR. Liquid-liquid equilibrium data for systems containing Brazil nut biodiesel+methanol+glycerin at $303.15 \mathrm{~K}$ and 323.15 K. Fuel 2014;133:292-298.

15. Muniz MAP, dos Santos MNF, da Costa CEF, Morais L, Lamarão MLN, Ribeiro-Costa RM, Silva JOC. Physicochemical characterization, fatty acid composition, and thermal analysis of Bertholletia excels HBK oil. Phoog Mag 2015;11:147-151.

16. Noureddini $\mathrm{H}$ et al. Densities of vegetable oils and fatty acids. JAOCS 1992;69(12):1184-1188.

17. Qiu T, Guo X, Yang J, Zhou L, Li L, Niu Y. The synthesis of biodiesel from coconut oil using novel Brönsted acidic ionic liquid as green catalyst. Chem Eng J 2016;296:71-78.

18. Bailey's industrial oil \& fat products, 6th edition, Wiley-Interscience, New York, 2005.

19. Lafont JJ, Espitia AA, Sodre JR. Potential vegetable sources for biodiesel production: cashew, coconut and cotton. Mater Renew Sustain Energy 2015;4(1):1-7.

20. Kalam MA, Rashed MM, Imdadul HK, Masjuki HH. Property development of fatty acid methyl ester from waste coconut oil as engine fuel. Ind Crops and Prod 2016;87:333-339. 